\title{
The immunopathogenetic role of autoantibodies in canine autoimmune hepatitis: lessons to learn from human autoimmune hepatitis
}

\author{
Christos Liaskos • Athanasios Mavropoulos • \\ Timoklia Orfanidou • Vassiliki Spyrou • \\ Labrini V. Athanasiou • Charalambos Billinis
}

Received: 19 September 2012/ Accepted: 24 September 2012/Published online: 9 October 2012

(C) Springer-Verlag Italia 2012

\begin{abstract}
Autoimmune hepatitis (AIH) is not a disease entity restricted to man, but it can be found in other animals including canines. An increasing number of studies have focused on the immunopathogenesis of human autoimmune hepatitis (hAIH), but little is known of what triggers canine autoimmune hepatitis (cAIH). Several drugs, toxins, microbial and viral agents are able to induce autoantibodies and indeed immune-mediated chronic canine hepatitis with immunological and serological features similar of those seen in the human disease. We discuss the features of cAIH paying attention to the autoantibody profile of the disease in comparison to that seen in hAIH. We also discuss the immunomodulatory role of specific molecular signaling pathways such as those mediated by tumor growth factor and p38 mitogen-activated kinase in the induction of AIH, and the potential of these molecules to act as targets of specialized immunotherapeutic interventions. Review of
\end{abstract}

C. Liaskos - A. Mavropoulos - T. Orfanidou

Institute of Research and Technology, Thessaly,

41222 Larissa, Greece

V. Spyrou

Department of Animal Production, Technological Educational Institute of Larissa, Larissa, Greece

L. V. Athanasiou

Department of Medicine, Faculty of Veterinary Medicine,

University of Thessaly, 43100 Karditsa, Greece

C. Billinis $(\square)$

Department of Microbiology and Parasitology,

Faculty of Veterinary Medicine, University of Thessaly,

43100 Karditsa, Greece

e-mail: billinis@vet.uth.gr the literature indicates that we have more to learn for the delineation of autoantibody profile and the antigen-specific immunoregulatory mechanisms involved in the pathogenesis of cAIH from the human disease, rather than the other way around.

Keywords Autoimmune $\cdot$ Dog $\cdot$ Human $\cdot$ Hepatitis

\section{Introduction}

Canis familiaris, the domestic dog, has been increasingly recognized as a promising candidate to investigate the pathogenesis of diseases affecting mankind $[1,2]$. The full elucidation of the canine genome has permitted researchers to establish genetic linkage mapping analyses of several susceptible loci [3-5]. The step forward would involve an era of advanced biochemical dissection regarding the molecular mechanisms associated with each disease. This includes research focusing on the canine molecular signaling apparatus whose manipulation may provide new therapeutic interventions for diseases that affect both man and $\operatorname{dog}[6,7]$.

One of the idiopathic diseases that affect both humans and dogs is autoimmune hepatitis (formerly known as chronic active hepatitis) [8, 9]. This review focuses on what is currently known about the disease-specific features of this disease in canine autoimmune hepatitis (cAIH) and the immediate relation of these features with human AIH (hAIH). We critically discuss the data reporting on the autoantibody profile of dogs affected with cAIH. The assumption is that if cAIH and hAIH share a lot of features in common, the more we learn about the canine disease, the better we will understand the enigmatic human disease. 
Infectious and non-infectious canine chronic hepatitis

Chronic hepatitis is among the most frequent but less understood diseases in canines [10, 11]. Both in man and in dog this serious worldwide health problem has no effective therapy. Its serious clinical manifestation involves nospecific symptoms and laboratory features characteristic of progressive deterioration of liver function affecting members of diverse breeds. Diagnosis is based on a variety of non-specific symptoms such as vomiting, lethargy, and weight loss, biochemical evidence of hepatic disease including increased levels of liver enzymes and histopathological features of hepatocyte destruction caused by a great variety of assaults [9, 12-14].

Chronic hepatitis is the most common form of chronic liver disease in dogs. The pathophysiological features of canine chronic hepatitis resemble those seen in human chronic hepatitis, as most of the cases are characterized by fibrosis, cirrhosis and subsequent liver failure causing death [9, 12-14]. In contrast to the human setting, however, where the cause of chronic hepatitis is known in the majority of the cases, the underlying cause of the disease in dogs is most often unknown, at times due to the increased cost of laboratory tests necessary for the accurate diagnosis of the underlying disease [9].

Chronic canine hepatitis can be broadly classified to infectious and non-infectious-related etiologies. Noninfectious canine chronic hepatitis is largely due to drugs, toxins, metabolic, genetic and autoimmune causes [9]. A great number of infectious agents can induce chronic canine hepatitis. Canine hepatitis adenovirus (CAV-1) has long ago been identified as an important viral pathogenetic agent [15-17]. Recently, Kapoor et al. [18] have reported the identification of a canine homolog of hepatitis $\mathrm{C}$ virus in domestic dogs of a non-primate hepacivirus. Leishmania infantum, Ehrlichia canis, Corynebacterium parvum, Bartonella, Leptospirae and Helicobacter species have also been highlighted as microbial determinants of canine hepatic injury [14, 19-22]. In terms of non-infectious agents copper accumulation is the leading cause of hepatitis and cirrhosis in certain breeds [2, 23] while as in humans, alpha-1 antitrypsin deficiency can also be the cause of hepatopathy [24]. Prolonged use of immunosuppressants and anticonvulsants can also cause chronic hepatitis in dogs [25, 26]. However, a considerable proportion of dogs with chronic hepatitis fail to be linked with a known cause of chronic hepatitis and their clinical, biochemical and histopathological features are highly indicative of an underlying immune-mediated-and indeed autoimmune-etiology responsible for the hepatocyte destruction [27-31]. A female predominance, similar to that seen in hAIH has been noted in dogs $[11,13,32,33]$. Also, several studies showed that at the time of diagnosis of
cAIH, dogs can also have clinical and biochemical signs of other extra-hepatic autoimmune manifestation, such as autoimmune hypothyroidism and autoimmune haemolytic anemia. The frequent co-existence of other autoimmune conditions is a common feature of hAIH. Intriguingly, a significant proportion of cases with cAIH are diagnosed during pregnancy or immediately after. Pregnancy is also able to unmask hAIH, clearly indicating that cAIH and hAIH share a lot of features, regarding the natural course of the disease. An underlying immune-mediated process in cAIH is supported by the fact that canine livers from dogs with cAIH have an increased ratio of $\mathrm{CD}^{+} / \mathrm{CD}^{+}$infiltrated cells and in some cases by CD3+ (pan T) lymphocytes infiltration (mainly on centrilobular areas). Also, it appears that the hepatocytes of the affected sites of liver parenchyma can upregulate the expression of MHC II antigens in their surface [34]. A state of immune dysregulation in dogs with cAIH is supported by the observation of a significant correlation between the haplotype of dog leukocyte antigen (DLA) gene system DRB1-DQA1DQB1 and the development of the disease. HLA genes, and in particular HLA DR3 and DR4 have been associated with hAIH type 1.

One of the major criteria to characterize a disease as autoimmune or immune-mediated is the good response to treatment with corticosteroids. Equal to humans, most reports of CAIH demonstrate a good response to immunosuppressive treatment and such treatment leads to the down-regulation of the HLA class II expression of the hepatocytes.

However, there are also some major histological differences between cAIH and hAIH. Piecemeal necrosis and intense portal track inflammation are the pathological hallmarks of hAIH but such histological features are not frequently seen in canine livers with cAIH. The histopathological changes of cAIH are usually characterized by a centrilobular distribution. Also, some studies investigating dogs with suspected cAIH failed to report good response to corticosteroid treatment. These findings underline the difficulty to accurately diagnose cAIH in a dog with idiopathic chronic idiopathic hepatitis. This difficulty is not seen in the case of individuals with human chronic liver disease and a suspicion of human AIH (Tables 1,2).

Liver disease-related autoantibodies in man and in dog

Human chronic liver disease that accounts for a substantial health burden worldwide occurs from a variety of causes. Viral infections are responsible for most chronic hepatitis, and include hepatitis viruses $\mathrm{B}, \mathrm{C}$, and D (always cooccurring with hepatitis B) [35, 36]. Hepatitis A and E cause acute disease. Since the isolation of human DNA hepatitis B virus (HBV) in 1970s, our understanding of 
Table 1 Major causes of chronic liver disease in man and dog

\begin{tabular}{|c|c|c|}
\hline Cause & Man & Dog \\
\hline Viruses & $\begin{array}{l}\text { Yes (i.e., hepatitis B, } \\
\text { C, D viruses, EBV, } \\
\text { CMV, HSV-1) }\end{array}$ & $\begin{array}{l}\text { Yes (i.e., CAV-1, } \\
\text { herpes virus, } \\
\text { canine acidophil } \\
\text { cell virus } \\
\text { hepatitis }^{\mathrm{a}} \text { ) }\end{array}$ \\
\hline Microbes & $\begin{array}{l}\text { Yes (Listeria } \\
\text { monocytogenes, } \\
\text { Brucella } \\
\text { mellitensis, } \\
\text { Legionella } \\
\text { pneumophila, } \\
\text { Treponema } \\
\text { pallidum, } \\
\text { Helicobacter } \\
\text { hepaticus) }\end{array}$ & $\begin{array}{l}\text { Yes (Leishmania } \\
\text { infantum, } \\
\text { Ehrlichia canis, } \\
\text { Corynebacterium } \\
\text { parvum, } \\
\text { Bartonella, } \\
\text { Leptospirae, } \\
\text { Helicobacter } \\
\text { species) [79] }\end{array}$ \\
\hline \multicolumn{3}{|l|}{ Toxins and drugs } \\
\hline Ethanol & Yes & Non-applicable \\
\hline Immunosuppressants & Yes & Yes \\
\hline Anticonvulsants & Yes & Yes \\
\hline \multicolumn{3}{|l|}{ Genetic diseases } \\
\hline $\begin{array}{l}\text { Alpha-1 antitrypsin } \\
\text { deficiency }\end{array}$ & Yes & $\begin{array}{l}\text { Yes (rarely } \\
\text { reported) }{ }^{\mathrm{b}} \text { [24] }\end{array}$ \\
\hline \multirow{3}{*}{$\begin{array}{l}\text { Copper storage } \\
\text { disease }\end{array}$} & Yes & Yes \\
\hline & $\begin{array}{l}\text { Most commonly is } \\
\text { Wilson disease } \\
\text { caused by mutation } \\
\text { in a gene on } \\
\text { chromosome } 13 \\
\text { that encodes for a } \\
\text { P-type ATPase }\end{array}$ & $\begin{array}{l}\text { Caused mainly by a } \\
\text { mutation of } \\
\text { MURR1 gene }\end{array}$ \\
\hline & $\begin{array}{l}\text { Rarely other types of } \\
\text { impaired copper } \\
\text { excretion }\end{array}$ & $\begin{array}{l}\text { Rarely other types } \\
\text { [28] }\end{array}$ \\
\hline Metabolic diseases & $\begin{array}{l}\text { Yes (various, well } \\
\text { studied as } \\
\text { haemochromatosis, } \\
\text { porphyrias) }\end{array}$ & $\begin{array}{l}\text { Yes (Various, less } \\
\text { extensively } \\
\text { studied) }\end{array}$ \\
\hline
\end{tabular}

$E B V$ Epstein-Barr virus, $C M V$ cytomegalovirus, $H S V$ - 1 herpes simplex virus-1, $C A V-1$ canine adenovirus

${ }^{a}$ Canine acidophil cell virus hepatitis can cause chronic hepatitis characterized by fibrosis and hepatocellular necrosis but without severe inflammatory signs and progression to hepatocellular carcinoma [15]

${ }^{b}$ Case reports with accumulation of two types of a-1 antitrypsin in the hepatocytes of dogs with $\mathrm{CAH}$, although reduced a-1 antitrypsin levels was not present

viral hepatitides has progressed exponentially [37]. The subsequent isolation of the RNA hepatitis $\mathrm{C}$ virus (HCV) initiated serious efforts towards a better understanding of the virus-host interactions and the immunopathological processes leading to hepatocyte damage. The identification of the prime etiology has led to intense research efforts for vaccine development. This is not yet possible for all the

Table 2 Autoantibodies in autoimmune hepatitis and pathogeninduced chronic liver disease in man and dog

\begin{tabular}{ll}
\hline & Comments \\
\hline $\begin{array}{l}\text { Human chronic liver disease } \\
\text { Hepatitis B virus }\end{array}$ & \\
ANA, SMA, & \\
anti-ASGPR & Titres are relatively low, and usually \\
& increased during treatment with \\
anti-viral agents such as \\
interferon-alpha \\
The homogenous IFL pattern typical \\
for AIH is relatively infrequent \\
No-specific targets have so far been \\
identified
\end{tabular}

Hepatitis $C$ virus

ANA, SMA,
anti-LKM1,
anti-LC1,
anti-ASGPR,
anti-SLA
Hepatitis D virus
Various types of
autoantibodies,
like HBV and HCV
Herpes simplex virus-1
ANA, SMA,
anti-LKM1

Epstein-Barr virus

Autoimmune hepatitis type 1

ANA, SMA, anti-SLA, anti-LM, anti-ASGPR

Autoimmune hepatitis type 2

Anti-LKM1, anti-LC1, anti-SLA, anti-LM, anti-ASGPR

Canine chronic hepatitis Infectious chronic hepatitis

Autoimmune hepatitis

ANA, SMA, anti-liver membrane protein antibodies
The only hepatitis virus that can induce AIH-2-specific autoantibodies

Reported data are relatively scarce

HSV-1 has been suggested as a trigger of AIH (type 1 and type 2) in case studies and molecular mimicry reports

This virus has been implicated in the pathogenesis of various autoimmune diseases including $\mathrm{AIH}$

Division into types is based on the presence of characteristic autoantibodies

No data available for infectious hepatitis but bacteraemia from pathogens such as Leishmania and Ehrlichia can lead to the development of ANA at low titres)

The most prevalent autoantibody reactivities are indicated in italics

forms of infectious canine hepatitis. And in humans, while vaccine development has been fruitful in the case of $\mathrm{HBV}$, it still remains a challenge for HCV. Progress has been made in halting the progression to cirrhosis during the latestages of the disease [38]. 
$\mathrm{HBV}$ and $\mathrm{HCV}$ are considered non-cytopathic viruses [39]. The immune response of the host against the virus has been considered pivotal for the clearance of the virus as well as the induction of immune-mediated liver disease [39]. A significant proportion of patients with chronic viral hepatitides have detectable autoantibodies, showing various immunofluorescent patterns when detected by indirect immunofluorescence (IIF) [40-42]. Some 20-50\% of chronic hepatitis $C$ virus infected patients have anti-nuclear (ANA) or smooth muscle antibodies (SMA), usually at low titres [40, 41, 43, 44]. These autoantibodies are also present to a lesser extent in patients infected with hepatitis B virus. Some hepatitis B and D co-infected patients are also found to have detectable autoantibodies [42]. ANA and SMA are serological markers of a specific form of hAIH, namely type 1 AIH [8, 45-49]. The pathognomonic autoantibodies for the second form of hAIH are those known as anti-liver kidney microsomal antibodies type 1 (anti-LKM-1) and anti-liver cytosol type 1 (anti-LC1) [25, 26, 50]. Notably, the AIH-2-specific anti-LKM-1 and anti-LC-1 antibodies can be found in 2-12\% of chronic hepatitis $\mathrm{C}$ virus infected patients, and this has prompted investigators to suggest that HCV is a likely cause of AIH-2.

ANA have been described in dogs suffering from a variety of conditions, ranging from systemic lupus erythematosus to bacterial and parasitic infections but the immediate relevance of these findings with the development of canine hepatitis remains elusive. Thus, ANA have also been described in dogs with SLE but the specificity of ANA reactivity in human and canine SLE appears to differ, as ANA in human SLE are mainly against dsDNA while ANA in canine SLE are targeting ribonucleoproteins. A report has described the presence of ANA in $75 \%$ of dogs infected with Bartonella vinsonii, and in $17 \%$ of those exposed to E. canis [51]. Others have failed to report the presence of ANA in E. canis infected dogs [52-54]. Systematic granulomatous disease involving the liver has been described in a dog with Bartonella infection [55]. In humans, Bartonella species can be the infectious causes of hepatosplenic cat-scratch disease, a form of cat-scratch disease seen in children which is characterized by microabscesses in the liver or the spleen and prolonged fever [56]. E. canis has also been described as one of the infectious triggers of chronic canine hepatitis [20]. Whether ANA or other autoantibodies can been seen in the sera of the affected dogs is not known.

Several investigators argue that with the exception of canine adenovirus and the very recently identified canine homolog of hepatitis $\mathrm{C}$ virus, we are still lacking knowledge regarding the viral etiology of acute and chronic canine hepatitis. The similarity between hepatitis in dogs and viral hepatitis in humans and other species in which hepatitis occurs suggests that hepatitis is at principal virally mediated. Therefore, current development in microarray technology has to be pursued more vigorously allowing the screening and identification of multiple other viruses as potential causative forms of hepatitis in dogs. Identifying the antigenic determinants of canine hepatitis will enable a more orthodox approach regarding research of downstream pathogenetic molecular pathways. This will eventually reverse the current memento mori concept of canine chronic hepatitis as being insidious with no evident primary clinical signs until well-established detrimental pathology has developed.

Nevertheless, one interesting feature of $\mathrm{cAIH}$ is reported in the past indicating the presence of antigen-specific humoral and cellular immune responses to liver membrane proteins. This may have pathogenic relevance as anti-liver membrane antibody was one of the very first disease-specific autoreactivities that have been described in hAIH. As early as 1976, Hopf et al. [57] described anti-liver membrane antibodies in patients with AIH. Subsequent studies using a variety of immunoassays and antigenic substrates have been able to confirm the presence of anti-liver membrane antibodies in patients with AIH [58-60].

Weiss et al. [61] was the first to describe anti-liver membrane antibodies in dogs with chronic hepatitis. The presence of relatively low ANA titres has also been described in the same study [61]. Among 21 sera from dogs with chronic hepatitis, 10 (48\%) had anti-liver membrane protein antibodies by ELISA, with some of the sera having reactivity at dilution as high as 1/1,600. Transaminase activity and total bilirubin concentration levels were significantly higher in the dogs with anti-liver membrane protein antibodies compared to the seronegative sera with chronic hepatitis, suggesting that the presence of this autoantibody may be a marker of liver disease activity and progression. The same researchers have investigated cellular immune responses to liver membrane proteins isolated from fresh dog liver by sucrose density gradient centrifugation. Peripheral blood mononuclear cell proliferation as a response to stimulation with liver membrane protein was higher in dogs with chronic hepatitis compared to dogs with other liver diseases or with healthy dogs. Among the six dogs that died within 3 months of diagnosis, five had significant proliferative responses to liver membrane protein. Such findings support the notion that chronic hepatitis has an autoimmune component, at the cellular and humoral level as autoantibody responses and $\mathrm{T}$ cell reactivity against liver-specific antigens are seen in affected dogs with a specific form of the disease.

How autoantibodies against liver-specific antigens arise in dogs with chronic hepatitis is not known. The possibility that these responses are epiphenomena secondary to hepatocyte destruction cannot be excluded, but such a scenario cannot explain why the responses are restricted to 
specific liver antigens and not the very many antigenic constituents released by the destruction of the hepatocytes. Autoantibodies against liver membrane antigens, such as asialoglycoprotein receptor, as well as against a soluble liver antigen have been described in a significant proportion of patients with AIH-1 and AIH-2 [8, 62, 63]. The mechanisms responsible for the induction of these autoantibodies are largely unknown but several studies have investigated the role of molecular mimicry and immunological cross-reactivity as a potential mechanism for the loss of immunological tolerance to these autoantigens during viral infections [43, 46, 64-72]. The pathogenesis of hAIH has been the focus of ongoing studies and the prevailing notion is that humoral and cellular immunity act in concert to induce the disease in susceptible individuals characterized by a state of immunosuppressor cell deficiency [73-78]. Autoantibody reactivities against these autoantigens have not yet been reported in sera from dogs with chronic hepatitis. Large prospective studies in dogs with chronic hepatitis, including those with the autoimmune form of the disease, need to be conducted. Serial serum sample collection from a large number of affected animals can provide the source of biological material to be screened for a variety of autoantibodies related to liver diseases in the human setting.

\section{Conclusion}

The autoantibody profile of dogs with chronic hepatitis and, in particular, cAIH has not been thoroughly studied, so far. The delineation of the autoantibody specificities seen in dogs with chronic hepatitis will help us to understand the immunopathological features of these dogs. It will give us the opportunity to better classify those with an autoimmune form of chronic hepatitis, and those with a form of chronic hepatitis not necessarily autoimmune. Identification of specific autoantibodies that can be used as diagnostic markers of cAIH is needed, as the prompt and accurate diagnosis of cAIH and early administration of immune-suppressive treatment may be of benefit for these dogs. At present, it looks like that cAIH is an entity that is poorly understood. We can take the lessons from the investigation conducted over the years, both at the experimental and at the clinical setting, in hAIH, to learn regarding the study of this disease.

Conflict of interest The authors declare that they have no conflict of interest.

\section{References}

1. Khanna C, Lindblad-Toh K, Vail D et al (2006) The dog as a cancer model. Nat Biotechnol 24:1065-1066
2. Favier RP, Spee B, Penning LC et al (2011) Copper-induced hepatitis: the COMMD1 deficient dog as a translational animal model for human chronic hepatitis. Vet Q 31:49-60

3. Debenham SL, Hart EA, Ashurst JL et al (2005) Genomic sequence of the class II region of the canine MHC: comparison with the MHC of other mammalian species. Genomics 85:48-59

4. Wilbe M, Jokinen P, Truve K et al (2010) Genome-wide association mapping identifies multiple loci for a canine SLE-related disease complex. Nat Genet 42:250-254

5. Lindblad-Toh K, Wade CM, Mikkelsen TS et al (2005) Genome sequence, comparative analysis and haplotype structure of the domestic dog. Nature 438:803-819

6. Rao NA, van Wolferen ME, van den Ham R et al (2008) cDNA microarray profiles of canine mammary tumour cell lines reveal deregulated pathways pertaining to their phenotype. Anim Genet 39:333-345

7. Sawhney R, Visvanathan K (2011) Polymorphisms of toll-like receptors and their pathways in viral hepatitis. Antivir Ther $16: 443-458$

8. Krawitt EL (2006) Autoimmune hepatitis. N Engl J Med 354:54-66

9. Watson PJ (2004) Chronic hepatitis in dogs: a review of current understanding of the aetiology, progression, and treatment. Vet $\mathrm{J}$ 167:228-241

10. Poldervaart JH, Favier RP, Penning LC et al (2009) Primary hepatitis in dogs: a retrospective review (2002-2006). J Vet Intern Med 23:72-80

11. Bexfield NH, Andres-Abdo C, Scase TJ et al (2011) Chronic hepatitis in the English springer spaniel: clinical presentation, histological description and outcome. Vet Rec 169:415

12. Shih JL, Keating JH, Freeman LM et al (2007) Chronic hepatitis in Labrador Retrievers: clinical presentation and prognostic factors. J Vet Intern Med 21:33-39

13. Crawford MA, Schall WD, Jensen RK et al (1985) Chronic active hepatitis in 26 Doberman pinschers. J Am Vet Med Assoc 187:1343-1350

14. Bishop L, Strandberg JD, Adams RJ et al (1979) Chronic active hepatitis in dogs associated with leptospires. Am J Vet Res 40:839-844

15. Jarrett WF, O’Neil BW (1985) A new transmissible agent causing acute hepatitis, chronic hepatitis and cirrhosis in dogs. Vet Rec 116:629-635

16. Rakich PM, Prasse KW, Lukert PD et al (1986) Immunohistochemical detection of canine adenovirus in paraffin sections of liver. Vet Pathol 23:478-484

17. Chouinard L, Martineau D, Forget C et al (1998) Use of polymerase chain reaction and immunohistochemistry for detection of canine adenovirus type 1 in formalin-fixed, paraffin-embedded liver of dogs with chronic hepatitis or cirrhosis. J Vet Diagn Invest 10:320-325

18. Kapoor A, Simmonds P, Gerold G et al (2011) Characterization of a canine homolog of hepatitis $\mathrm{C}$ virus. Proc Natl Acad Sci USA 108:11608-11613

19. Leifer CE, Page RL, Matus RE et al (1987) Proliferative glomerulonephritis and chronic active hepatitis with cirrhosis associated with Corynebacterium parvum immunotherapy in a dog. J Am Vet Med Assoc 190:78-80

20. Mylonakis ME, Kritsepi-Konstantinou M, Dumler JS et al (2010) Severe hepatitis associated with acute Ehrlichia canis infection in a dog. J Vet Intern Med 24:633-638

21. Rallis T, Day MJ, Saridomichelakis MN et al (2005) Chronic hepatitis associated with canine leishmaniosis (Leishmania infantum): a clinicopathological study of 26 cases. J Comp Pathol 132:145-152

22. Kearns S (2009) Infectious hepatopathies in dogs and cats. Top Companion Anim Med 24:189-198 
23. Spee B, Arends B, van den Ingh TS et al (2006) Copper metabolism and oxidative stress in chronic inflammatory and cholestatic liver diseases in dogs. J Vet Intern Med 20:1085-1092

24. Sevelius E, Andersson M, Jonsson L (1994) Hepatic accumulation of alpha-1-antitrypsin in chronic liver disease in the dog. J Comp Pathol 111:401-412

25. Rogers WA, Ruebner BH (1977) A retrospective study of probable glucocorticoid-induced hepatopathy in dogs. J Am Vet Med Assoc 170:603-606

26. Bunch SE, Castleman WL, Hornbuckle WE et al (1982) Hepatic cirrhosis associated with long-term anticonvulsant drug therapy in dogs. J Am Vet Med Assoc 181:357-362

27. Gocke DJ, Morris TQ, Bradley SE (1970) Chronic hepatitis in the dog: the role of immune factors. J Am Vet Med Assoc 156:1700-1705

28. Mandigers PJ, van den Ingh TS, Spee B et al (2004) Chronic hepatitis in Doberman pinschers. A review. Vet Q 26:98-106

29. Sterczer A, Gaal T, Perge E et al (2001) Chronic hepatitis in the dog-a review. Vet Q 23:148-152

30. Strombeck DR, Gribble D (1978) Chronic active hepatitis in the dog. J Am Vet Med Assoc 173:380-386

31. Thornburg LP (1998) Histomorphological and immunohistochemical studies of chronic active hepatitis in Doberman Pinschers. Vet Pathol 35:380-385

32. Boisclair J, Dore M, Beauchamp G et al (2001) Characterization of the inflammatory infiltrate in canine chronic hepatitis. Vet Pathol 38:628-635

33. Fuentealba C, Guest S, Haywood S et al (1997) Chronic hepatitis: a retrospective study in 34 dogs. Can Vet J 38:365-373

34. Speeti M, Stahls A, Meri S et al (2003) Upregulation of major histocompatibility complex class II antigens in hepatocytes in Doberman hepatitis. Vet Immunol Immunopathol 96:1-12

35. Marcellin P (2009) Hepatitis B and hepatitis C in 2009. Liver Int 29(Suppl 1):1-8

36. Zignego AL, Piluso A, Giannini C (2008) HBV and HCV chronic infection: autoimmune manifestations and lymphoproliferation. Autoimmun Rev 8:107-111

37. Lai M, Liaw YF (2010) Chronic hepatitis B: past, present, and future. Clin Liver Dis 14:531-546

38. Shi YH, Shi CH (2009) Molecular characteristics and stages of chronic hepatitis B virus infection. World J Gastroenterol 15:3099-3105

39. Guidotti LG, Chisari FV (2006) Immunobiology and pathogenesis of viral hepatitis. Annu Rev Pathol 1:23-61

40. Bogdanos DP, Mieli-Vergani G, Vergani D (2004) Non-organspecific autoantibodies in children with chronic hepatitis $\mathrm{C}$ virus infection. Clin Infect Dis 38:1505 (author reply 1505-1506)

41. Bogdanos DP, Mieli-Vergani G, Vergani D (2005) Non-organspecific autoantibodies in hepatitis $\mathrm{C}$ virus infection: do they matter? Clin Infect Dis 40:508-510

42. Obermayer-Straub P, Manns MP (2001) Hepatitis C and D, retroviruses and autoimmune manifestations. $\mathrm{J}$ Autoimmun $16: 275-285$

43. Bogdanos DP, Muratori L, Bianchi FB et al (2000) Hepatitis C virus and autoimmunity. Hepatology 31:1380

44. Gregorio GV, Choudhuri K, Ma Y et al (2003) Mimicry between the hepatitis $\mathrm{C}$ virus polyprotein and antigenic targets of nuclear and smooth muscle antibodies in chronic hepatitis $\mathrm{C}$ virus infection. Clin Exp Immunol 133:404-413

45. Bogdanos DP, Mieli-Vergani G, Vergani D (2009) Autoantibodies and their antigens in autoimmune hepatitis. Semin Liver Dis 29:241-253

46. Bogdanos DP, Dalekos GN (2008) Enzymes as target antigens of liver-specific autoimmunity: the case of cytochromes P450s. Curr Med Chem 15:2285-2292
47. Alvarez F, Berg PA, Bianchi FB et al (1999) International Autoimmune Hepatitis Group Report: review of criteria for diagnosis of autoimmune hepatitis. J Hepatol 31:929-938

48. Hennes EM, Zeniya M, Czaja AJ et al (2008) Simplified criteria for the diagnosis of autoimmune hepatitis. Hepatology 48:169-176

49. Bogdanos DP, Invernizzi P, Mackay IR et al (2008) Autoimmune liver serology: current diagnostic and clinical challenges. World J Gastroenterol 14:3374-3387

50. Bogdanos DP, Mieli-Vergani G, Vergani D (2001) Liver-kidney microsomal antibody-positive autoimmune hepatitis in the United States. Am J Gastroenterol 96:3447-3448

51. Smith BE, Tompkins MB, Breitschwerdt EB (2004) Antinuclear antibodies can be detected in dog sera reactive to Bartonella vinsonii subsp. berkhoffii, Ehrlichia canis, or Leishmania infantum antigens. J Vet Intern Med 18:47-51

52. Kelly PJ, Carter SD, Bobade PA et al (1994) Absence of antinuclear antibodies in dogs infected with Ehrlichia canis. Vet Rec 134:382

53. Harrus S, Day MJ, Waner T et al (2001) Presence of immunecomplexes, and absence of antinuclear antibodies, in sera of dogs naturally and experimentally infected with Ehrlichia canis. Vet Microbiol 83:343-349

54. Gershwin LJ (2005) Antinuclear antibodies in domestic animals. Ann N Y Acad Sci 1050:364-370

55. Saunders GK, Monroe WE (2006) Systemic granulomatous disease and sialometaplasia in a dog with Bartonella infection. Vet Pathol 43:391-392

56. Lenoir AA, Storch GA, DeSchryver-Kecskemeti K et al (1988) Granulomatous hepatitis associated with cat scratch disease. Lancet 1:1132-1136

57. Hopf U, Meyer zum Buschenfelde KH, Arnold W (1976) Detection of a liver-membrane autoantibody in HBsAg-negative chronic active hepatitis. N Engl J Med 294:578-582

58. Manns M, Meyer zum Buschenfelde KH, Hutteroth TH et al (1980) Detection and characterization of liver membrane autoantibodies in chronic active hepatitis by a solid-phase radioimmunoassay. Clin Exp Immunol 42:263-272

59. Meliconi R, Stancari MV, Garagnani M et al (1983) Occurrence and significance of IgG liver membrane autoantibodies (LMA) in chronic liver diseases of different aetiology. Clin Exp Immunol 51:565-571

60. Manns M, Meyer zum Buschenfelde KH, Hess G (1980) Autoantibodies against liver-specific membrane lipoprotein in acute and chronic liver diseases: studies on organ-, species-, and disease-specificity. Gut 21:955-961

61. Weiss DJ, Armstrong PJ, Mruthyunjaya A (1995) Anti-liver membrane protein antibodies in dogs with chronic hepatitis. J Vet Intern Med 9:267-271

62. Bogdanos DP, Bianchi I, Ma Y et al (2004) Targets of antibodies to soluble liver antigen in patients with autoimmune hepatitis. Clin Chem 50:682-683 (author reply 683-684)

63. Rigopoulou EI, Roggenbuck D, Smyk DS et al (2012) Asialoglycoprotein receptor (ASGPR) as target autoantigen in liver autoimmunity: lost and found. Autoimmun Rev

64. Bogdanos DP, Choudhuri K, Vergani D (2001) Molecular mimicry and autoimmune liver disease: virtuous intentions, malign consequences. Liver 21:225-232

65. Bogdanos DP, Lenzi M, Okamoto M et al (2004) Multiple viral/ self immunological cross-reactivity in liver kidney microsomal antibody positive hepatitis $\mathrm{C}$ virus infected patients is associated with the possession of HLA B51. Int J Immunopathol Pharmacol 17:83-92

66. Bogdanos DP, McFarlane IG (2003) Cytochrome P450 2A6 meets P450 2D6: an enigma of viral infections and autoimmunity. J Hepatol 39:860-863 
67. Bogdanos DP, Mieli-Vergani G, Vergani D (2000) Virus, liver and autoimmunity. Dig Liver Dis 32:440-446

68. Bogdanos DP, Rigopoulou EI (2006) Self-mimicking autoimmune domains of hepatitis $\mathrm{C}$ virus core antigen. Vaccine 24:6173-6174

69. Bogdanos DP, Rigopoulou EI (2007) Viral/self-mimicry and immunological cross-reactivity as a trigger of hepatic $\mathrm{C}$ virus associated autoimmune diabetes. Diabetes Res Clin Pract 77:155-156

70. Bogdanos DP, Smith H, Ma Y et al (2005) A study of molecular mimicry and immunological cross-reactivity between hepatitis B surface antigen and myelin mimics. Clin Dev Immunol $12: 217-224$

71. Muratori L, Bogdanos DP, Muratori P et al (2005) Susceptibility to thyroid disorders in hepatitis C. Clin Gastroenterol Hepatol 3:595-603

72. Kerkar N, Choudhuri K, Ma Y et al (2003) Cytochrome P4502D6(193-212): a new immunodominant epitope and target of virus/self cross-reactivity in liver kidney microsomal autoantibody type 1-positive liver disease. J Immunol 170:14811489
73. Longhi MS, Hussain MJ, Bogdanos DP et al (2007) Cytochrome P450IID6-specific CD8 T cell immune responses mirror disease activity in autoimmune hepatitis type 2. Hepatology 46:472-484

74. Longhi MS, Ma Y, Bogdanos DP et al (2004) Impairment of $\mathrm{CD} 4(+) \mathrm{CD} 25(+)$ regulatory T-cells in autoimmune liver disease. J Hepatol 41:31-37

75. Longhi MS, Ma Y, Mitry RR et al (2005) Effect of CD4+ $\mathrm{CD} 25+$ regulatory T-cells on CD8 T-cell function in patients with autoimmune hepatitis. J Autoimmun 25:63-71

76. Ma Y, Bogdanos DP, Hussain MJ et al (2006) Polyclonal T-cell responses to cytochrome P450IID6 are associated with disease activity in autoimmune hepatitis type 2. Gastroenterology 130:868-882

77. Bogdanos DP, Smyk DS, Rigopoulou EI et al (2012) Twin studies in autoimmune disease: genetics, gender and environment. J Autoimmun 38:J156-J169

78. Vergani D, Longhi MS, Bogdanos DP et al (2009) Autoimmune hepatitis. Semin Immunopathol 31:421-435

79. Bexfield NH, Buxton RJ, Vicek TJ et al (2012) Breed, age and gender distribution of dogs with chronic hepatitis in the United Kingdom. Vet J 193:124-128 